\title{
A violência simbólica de mulheres pelas narrativas policiais e jornalísticas
}

\author{
Ana Paula de Castro Neves ${ }^{1}$ \\ Angelita Pereira de Lima²
}

\begin{abstract}
Resumo
O presente trabalho tem por objetivo geral apresentar uma análise sobre a violência simbólica contida nas narrativas dos boletins de ocorrência que são identificáveis e reproduzidas no corpus das notícias dos jornais Diário da Manhã e O Popular no período de 2016 e 2017. Procura-se categorizar e analisar por meio da metodologia análise de conteúdo com abordagem qualitativa, a construção e os argumentos dessas narrativas no que tange à temática violência simbólica através do processo de revitimização de mulheres em situação de violência.
\end{abstract}

Palavras-chave: Revitimização. Violência simbólica. Narrativas policiais e jornalísticas

\begin{abstract}
The present work has the general objective of presenting an analysis of the symbolic violence contained in the narratives of the police reports that are identifiable and reproduced in the news corpus of the newspapers Diário da Manhã and O Popular in the period of 2016 and 2017. It seeks to categorize and analyze, through the methodology of content analysis with a qualitative approach, the construction and arguments of these narratives with regard to the theme of symbolic violence through the process of revictimization of women in situations of violence.
\end{abstract}

Key words: Revitimization. Symbolic violence. Police and journalistic narratives

\section{Introdução}

As diferenças e assimetrias são sempre transformadas em desigualdades que reforçam a relação de mando-obediência, na qual o outro não é reconhecido como sujeito

\footnotetext{
${ }^{1}$ Doutoranda e Mestre em Direitos Humanos do Programa de Programa de Pós-Graduação Interdisciplinar em Direitos Humanos - (PPGIDH) da Universidade Federal de Goiás. apcastro_1@hotmail.com

2 Doutora em Geografia pela Universidade Federal de Goiás. Professora do Programa de PósGraduação Interdisciplinar em Direitos Humanos da Universidade Federal de Goiás (UFG). angelitalimaufg@gmail.com
} 


\section{VOZES \\ ¿DIÁl DCo}

Itajaí, V. 20, n.01, jan-jun 2021

de direitos, como subjetividade e como alteridade (CHAUÍ, 1999). Assim, as vozes silenciadas e os corpos estigmatizados de mulheres vítimas de outras formas de opressão além do sexismo continuam na invisibilidade (CARNEIRO, 2003).

Nesse contexto, os estudos importantes acerca das assimetrias de gênero que, historicamente, apontam para uma dominação masculina enraizada por expressões sociais e reproduzida através de narrativas jornalísticas que tornam invisíveis a violência de gênero e as desigualdades sociais - visando não apenas punir o corpo da mulher, mas, inclusive, depreciar sua cidadania. Desse modo, o objetivo geral dessa pesquisa foi analisar as construções sociais das narrativas policiais, por representarem a principal fonte de notícias dos jornais Diário da Manhã e O Popular do estado de Goiás, no período de 2016 e 2017.

Acredita-se que o problema não se resume apenas na construção das narrativas jornalísticas e policiais, porém, decorre da construção ideológica por meio de uma violência estrutural, no qual as palavras, expressões e termos machistas ocultam das mulheres seus direitos individuais e resulta, assim, no processo de revitimização, o que configura uma violência simbólica. Desse modo, busca-se compreender como essas construções sociais narrativas reforçam comportamentos que já são naturalizados pelas desigualdades na sociedade e fazem com que a violência noticiada nem sempre seja reconhecida como uma violência de gênero.

Como material para análise para este artigo, elencou-se um total de 11 notícias do jornal O Popular (seis do ano de 2016 e cinco de 2017) e 6 notícias do jornal Diário da Manhã (duas de 2016 e quatro de 2017). Assim, buscou-se, por meio da análise de conteúdo considerar os elementos propostos por Bardin (2016), ou seja, pertinência e relevância das informações e dos fatos contidos nas narrativas dos boletins de ocorrência que são identificáveis e reproduzidos no corpus das notícias dos jornais.

\section{Análise das narrativas policiais - jornal Diário da Manhã}

Compreender a complexidade que envolve as relações de gênero em situações de violência contra mulheres é uma tarefa desafiadora e grandiosa. Por essa razão, delimitouse abordar a violência contra mulheres na construção das narrativas pelo que é dito sobre a mulher e sobre o agressor, pois, tais elementos, apesar de demonstrarem aparente neutralidade sobre questões de gênero, produzem e reproduzem narrativas opressivas quanto às mulheres em situação de violência e, consequentemente, geram a sobreposição de violências (LOURO, 2018).

Ressalta-se que das 6 notícias do jornal Diário da Manhã, obteve-se acesso a apenas 5 boletins. A par dos documentos levantados e das bibliografias definidas, passou-se à execução da pesquisa e exploração do material. A análise categorial, segundo Bardin (2016, p. 153), é aquela que "funciona por operações de desmembramento do texto em unidades, em categorias segundo reagrupamentos analógicos”. 


\section{VOZES $_{\text {\&IÁLOGO }}^{\mid}$}

Itajaí, V. 20, n.01, jan-jun 2021

Seguem os destaques nos quadros selecionados:

QUADRO 01: "Homem queima amante com soda cáustica." Diário da Manhã.

\begin{tabular}{l|l|l|}
\hline CATEGORIAS & BOLETIM DE OCORRÊNCIA & JORNAL DIÁRIO DA MANHÃ \\
$\begin{array}{l}\text { O QUE É DITO } \\
\text { SOBRE A MULHER }\end{array}$ & $\begin{array}{l}\text { - Mesmo não casados, mantinham um } \\
\text { relacionamento extraconjugal. }\end{array}$ & $\begin{array}{l}\text { - Ele é casado e mantinha um } \\
\text { relacionamento extraconjugal com a } \\
\text { vítima há cerca de dois anos. }\end{array}$ \\
$\begin{array}{l}\text { SOBRE É DITO OAGRESSOR } \\
\text { SOBRE }\end{array}$ & $\begin{array}{l}\text { - O agressor havilia e ânus da vítima com Super } \\
\text { Bonder. }\end{array}$ & $\begin{array}{l}\text { - Suspeito de torturar a mulher com mantinha um relacionamento } \\
\text { qumoroso extraconjugal. }\end{array}$ \\
\hline
\end{tabular}

Fonte: Pesquisa: A culpabilização das mulheres nas narrativas sobre violência de gênero nos boletins de ocorrência e nos jornais diários de Goiânia (PV0867-2017)

QUADRO 02: "Violência sem limites." Diário da Manhã.

\begin{tabular}{|c|c|c|}
\hline CATEGORIAS & BOLETIM DE OCORRÊNCIA & JORNAL DIÁRIO DA MANHÃ \\
\hline $\begin{array}{l}\text { O QUE É DITO } \\
\text { SOBRE A MULHER }\end{array}$ & $\begin{array}{l}\text { - Teve um relacionamento com o autor } \\
\text { e, após o término, não foi aceito. }\end{array}$ & $\begin{array}{l}\text { - Ex-namorada e esperou até que o } \\
\text { atual namorado da vítima fosse } \\
\text { embora para entrar e começar a } \\
\text { agir. }\end{array}$ \\
\hline $\begin{array}{l}\text { O QUE É DITO } \\
\text { SOBRE O AGRESSOR }\end{array}$ & $\begin{array}{l}\text { - Inconformado, pulou o muro, } \\
\text { arrombou a porta da residência para } \\
\text { cometer agressão. }\end{array}$ & $\begin{array}{l}\text {-Discussão por ciúmes que o } \\
\text { agressor sentia pela vítima, a mulher } \\
\text { estava em outro relacionamento. }\end{array}$ \\
\hline
\end{tabular}

Fonte: Pesquisa: A culpabilização das mulheres nas narrativas sobre violência de gênero nos boletins de ocorrência e nos jornais diários de Goiânia (PV0867-2017)

QUADRO 1: Mulher é torturada com facão e pimenta no órgão genital. Diário da Manhã. 


\section{VOZES $_{\text {\&DÁLORO }}^{\mid}$}

Itajaí, V. 20, n.01, jan-jun 2021

\begin{tabular}{|c|c|c|}
\hline CATEGORIAS & BOLETIM DE OCORRÊNCIA & JORNAL DIÁRIO DA MANHÃ \\
\hline $\begin{array}{l}\text { O QUE É DITO } \\
\text { SOBRE A MULHER }\end{array}$ & $\begin{array}{l}\text { - Vítima estava morando com autor há } \\
\text { quatro meses. }\end{array}$ & $\begin{array}{l}\text { - Suspeita de traição. } \\
\text { - Denunciou o agressor duas vezes } \\
\text { anteriores e, assim mesmo, reatou o } \\
\text { relacionamento. }\end{array}$ \\
\hline $\begin{array}{l}\text { O QUE É DITO } \\
\text { SOBRE O AGRESSOR }\end{array}$ & $\begin{array}{l}\text { - A mulher tentou fugir do agressor, e } \\
\text { por isso ele atacou. }\end{array}$ & $\begin{array}{l}\text { - Sempre foi muito possessivo e } \\
\text { ciumento } \\
\text { - Alega que as agressões praticadas } \\
\text { foram em legítima defesa. }\end{array}$ \\
\hline
\end{tabular}

Fonte: Pesquisa: A culpabilização das mulheres nas narrativas sobre violência de gênero nos boletins de ocorrência e nos jornais diários de Goiânia (PV0867-2017)

QUADRO 04: "Doméstica está assustada: se ele sair, ele me mata." Diário da Manhã.

\begin{tabular}{|c|c|c|}
\hline CATEGORIAS & BOLETIM DE OCORRÊNCIA & JORNAL DIÁRIO DA MANHÃ \\
\hline $\begin{array}{l}\text { O QUE É DITO } \\
\text { SOBRE A MULHER }\end{array}$ & $\begin{array}{l}\text { - Vítima conviveu com suposto autor por } \\
\text { cerca de cinco anos e a convivência } \\
\text { sempre foi conturbada. } \\
\text { - Ela está temerosa, pois acredita que ele } \\
\text { vai voltar para matá-la. }\end{array}$ & $\begin{array}{l}\text { - Está marcada para morrer. É o que } \\
\text { ela pensa depois que foi alvejada } \\
\text { cinco vezes pelo namorado que não } \\
\text { aceitava o rompimento. }\end{array}$ \\
\hline $\begin{array}{l}\text { O QUE É DITO } \\
\text { SOBRE O AGRESSOR }\end{array}$ & $\begin{array}{l}\text { - Ex-marido não aceita o rompimento e } \\
\text { ameaçou matar a vítima e seu filho. }\end{array}$ & $\begin{array}{l}\text { - Ele diz que estava alcoolizado } \\
\text { quando praticou o crime. }\end{array}$ \\
\hline
\end{tabular}

Fonte: Pesquisa: A culpabilização das mulheres nas narrativas sobre violência de gênero nos boletins de ocorrência e nos jornais diários de Goiânia (PV0867-2017)

QUADRO 05: "Ex-marido persegue mulher e ameaça matar ela e sua família." Diário da Manhã.

\begin{tabular}{|l|l|l|}
\hline CATEGORIAS & BOLETIM DE OCORRÊNCIA & JORNAL DIÁRIO DA MANHÃ \\
\hline $\begin{array}{l}\text { O QUE É DITO } \\
\text { SOBRE A MULHER }\end{array}$ & $\begin{array}{l}\text { - Separada do seu amásio, está sendo } \\
\text { ameaçada por tê-lo denunciado. Ela } \\
\text { ainda informou que o agressor é do } \\
\text { mundo do crime e tem várias passagens } \\
\text { pela polícia. }\end{array}$ & $\begin{array}{l}\text { - Ela já retirou uma denúncia anterior } \\
\text { para que o agressor fosse solto. }\end{array}$ \\
\hline
\end{tabular}




\section{VOZES $_{\text {\&DÁLORO }}^{\mid}$}

Itajaí, V. 20, n.01, jan-jun 2027

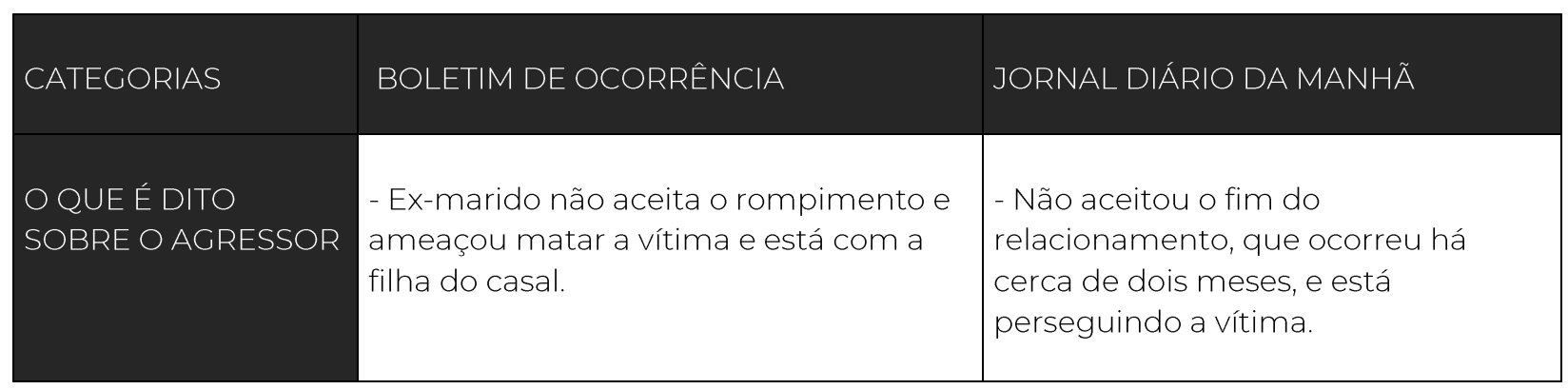

Fonte: Pesquisa: A culpabilização das mulheres nas narrativas sobre violência de gênero nos boletins de ocorrência e nos jornais diários de Goiânia (PV0867-2017)

Adotando uma classificação abrangente de violência, que inclui a violência física, emocional, moral e até a institucional, Rossi (2016) compreende essa última como a que mais interessa à pesquisa, pois ela pode se concretizar pela ocorrência de qualquer descaso, empecilho, negação ou embaraço de acesso à justiça pela vítima. Inclusive, a violência institucional, assim como as demais, é uma das formas de violação dos Direitos Humanos das Mulheres. Um estudo sobre este assunto se justifica, pois, no atual cenário é imperativo a busca pela construção da democracia na sociedade goiana.

Deste modo, é possível pensar nas narrativas policiais quando reproduzidas pelas narrativas jornalísticas como meio de produzir informações e significados culturais através de uma linguagem que implica relações de poder, veiculando detalhes que desqualificam a mulher, sensacionalizando os fatos ou justificando o agressor - caracterizando, enfim, uma sobreposição de violência ou revitimização.

Quando comparamos a construção das narrativas policiais e narrativas jornalísticas do Diário da Manhã, pode-se afirmar que há uma relação na construção das representações sociais entre essas narrativas. O jornal, além de reproduzir o que diz a narrativa policial, também utiliza elementos tais como substantivos e adjetivos, entre outros termos, que acentuam e destacam a condição da mulher como vítima, de uma forma mais evidente que a do registro policial, como exemplo do quadro no 01: Ele é casado e mantinha um relacionamento extraconjugal com a vítima há cerca de dois anos; Suspeito de torturar a mulher com quem mantinha um relacionamento amoroso extraconjugal. Assim, as relações de poder não estão presentes apenas no contexto das narrativas jornalísticas, mas em toda narrativa que representa uma intervenção no curso dos acontecimentos, de modo a influenciar as ações dos outros e produzir eventos por meio da produção e transmissão de formas simbólicas (THOMPSON, 2001).

Nesse sentido, quando olhamos para as notícias analisadas podemos concluir que o corpus dos boletins de ocorrência são os maiores responsáveis por apresentar os enredos do jornal Diário da Manhã, sendo capazes de determinar os tipos de discursos que vão ser produzidos na pauta jornalística. E assim, as narrativas policiais ganham destaque quando são publicizadas pelos jornais, fornecendo elementos de grande importância sobre os 


\section{VOZES $_{\text {\&IÁLORO }}^{\mid}$}

Itajaí, V. 20, n.01, jan-jun 2021

problemas sociais referentes às desigualdades de gênero e, portanto, na representação social das mulheres.

É importante observar que descrições como "não aceitou o fim do relacionamento", frequentes nas narrativas policiais pelos quadros analisados e reproduzidas pelas narrativas jornalísticas, funcionam como uma "justificativa do agressor" para que o jornal acrescente o sensacionalismo e espetacularização, o que acaba funcionando também como uma forma de mascarar os conflitos de gênero pela rotinização, bem como pela naturalização (LIMA, 2001).

Segundo os dados dos boletins de ocorrência os crimes cometidos são em geral cometidos por homens que têm algum tipo de relacionamento com essas mulheres, que, diante de um pedido de separação, consideram que há um motivo suficiente para infligir atos violentos por meio de crueldade e, desse modo, procuram demarcar o corpo feminino como um território de vingança (BANDEIRA E MAGALHÃES, 2019). Ainda, segundo as autoras, o medo é naturalizado pelas narrativas, muitas delas nos permitem inferir que a violência é inevitável, seja material, sexual ou emocional, e trazem como consequência o retraimento e a inibição para denunciá-la, ou seja, para visibilizá-la.

Ainda, dados pessoais das mulheres, como lapso temporal que ela viveu com agressor, tipo de relação que ela mantinha (amante, ex-namorada, amasiada), são produzidos pelo boletim de ocorrência a fim de evidenciar os fatos, sendo reproduzido pelas notícias jornalísticas, fazendo com que a tragicidade da história dessas mulheres migre do espaço privado para o público. Essas mulheres são obrigadas a reviver a violência, a humilhação sofrida não apenas no contexto familiar, mas em todo território goiano. Isso aponta para o processo de revitimização que as mulheres em situação de violência, após o ato violento, sofrem em decorrência do fato vivenciado, por meio da desqualificação em relação às ameaças, violências e ofensas sofridas, somando-se a tudo isso a inoperância e a pouca celeridade do sistema judiciário, que provocam ainda forte descrença e impunidade (BANDEIRA E MAGALHÃES, 2019).

As construções dessas narrativas ainda apresentam a ideia de que essas mulheres foram torturadas e agredidas por um simples desentendimento amoroso, em que os comportamentos machistas são usados para que homens reivindiquem o corpo e a vida das mulheres - não há descrição isenta de julgamentos e avaliações morais pelos agentes responsáveis pelas narrativas dos boletins de ocorrência. Ainda, pelas análises comparativas das narrativas, pode-se verificar que os crimes de violência contra mulheres envolvem as características ao relacionar a condição de gênero e a dominação masculina (BANDEIRA E MAGALHÃES, 2019).

Para Segato (2006, p. 06), a equivalência e a continuidade semântica entre o corpo das mulheres e o território são o fundamento de várias normas que aparecem como pertencentes à ordem moral. Ainda, permitiu evidenciar através dos relatos que mesmo certo padrão prévio de maneiras de redigir pode estar entre os elementos capazes de 


\section{VOZES $_{\text {\&IÁLORO }}^{\mid}$}

Itajaí, V. 20, n.01, jan-jun 2027

distorcer as vozes, menos ou mais levemente (BAIRROS, 2010, p. 28). Segundo Chauí (1999), a ideia de que a natureza das mulheres as destina ao silêncio e à obscuridade está profundamente arraigada em nossas culturas. Restritas ao espaço privado, as mulheres permanecem invisibilizadas nas democracias modernas, herdeiras e continuadoras da violência estrutural que assola nossas instituições.

Segundo Bandeira e Magalhães (2019), a mídia é crucial para a formação e reprodução das identidades de gênero, pois é capaz de romper com os papéis tradicionais atribuídos às mulheres. No entanto, as narrativas do jornal Diário da Manhã não apresentam avanços, já que os papéis tradicionais das mulheres são reafirmados por meio de estigmas depreciativos que acabam por entrar no enquadramento midiático pela tragédia da violência. A esse respeito, Gomes (2017, p. 38) adverte que "é importante que os veículos de comunicação abordem o assunto de forma mais contextualizada e utilizando termos que produzam reflexão sobre a temática". Isso porque "os veículos reproduzem discursos de violência simbólica e dominação masculina, chegando até mesmo ao ponto de colocar as vítimas da violência como culpadas pelas agressões que sofreram". Para Miranda (2017), os caminhos para reduzir esse problema no jornalismo seriam evitar a descontextualização dos casos, pois isso provoca a invisibilização das mulheres em situação de violência. Além do mais, faz-se necessário que a potência do agressor não seja destacada, com a finalidade de evitar a manutenção dos papéis de gênero. Ela ainda aponta que o agressor não deve ser desresponsabilizado pelo cometimento do crime por meio de justificativas, assim como o crime também não deve ser narrado de uma forma romantizada.

\section{Análise das narrativas policiais - jornal O Popular}

Prosseguindo as análises das narrativas policiais, foram investigadas as narrativas dos boletins de ocorrência que foram fontes do jornal $O$ Popular. Utilizaram-se duas unidades de registro: o que é dito sobre a mulher e o que dito sobre o agressor, visando inferir se as palavras, termos ou expressões foram apenas reproduzidas pelas narrativas jornalísticas. Ou seja, as inferências nas palavras, termos ou expressões que constituem a visibilidade da representação social de gênero e que são reproduzidas pelas narrativas jornalísticas.

No jornal O Popular, foram catalogadas 11 (onze) notícias para realizar análise de conteúdo (BARDIN, 2016). Todavia, das 11 que serviram de fonte para o referido jornal, tivemos acesso a apenas 10 boletins de ocorrência fornecidos pela segurança pública. Assim sendo, seguem os destaques selecionados:

QUADRO 06: "Mulher é agredida com soda por amante." O Popular 


\section{VOZES $_{\text {\&DÁLORO }}^{\mid}$}

Itajaí, V. 20, n.01, jan-jun 2021

\begin{tabular}{l|l|l|}
\hline CATEGORIAS & BOLETIM DE OCORRÊNCIA & JORNAL O POPULAR \\
\hline \begin{tabular}{l|l} 
O QUE É DITO \\
SOBRE A MULHER
\end{tabular} & $\begin{array}{l}\text { - Mesmo não casados, mantinham um } \\
\text { relacionamento. }\end{array}$ & $\begin{array}{l}\text {-Ele mantinha relação amorosa } \\
\text { extraconjugal com a mulher, que foi } \\
\text { atingida no rosto, pescoço e braços, } \\
\text { provocando queimaduras de } \\
\text { primeiro e segundo graus. }\end{array}$ \\
\hline $\begin{array}{l}\text { O QUE É DITO } \\
\text { SOBRE OAGRESSOR }\end{array}$ & $\begin{array}{l}\text { - O agressor havia colado os olhos, } \\
\text { genitália e ânus da vítima com Super }\end{array}$ & $\begin{array}{l}\text { - De acordo com a polícia civil, a } \\
\text { motivação do crime teria sido porque } \\
\text { a vítima teria ameaçado a mulher do } \\
\text { homem de morte }\end{array}$ \\
\hline
\end{tabular}

Fonte: Pesquisa: A culpabilização das mulheres nas narrativas sobre violência de gênero nos boletins de ocorrência e nos jornais diários de Goiânia (PV0867-2017)

QUADRO 07: "Mulher fica em estado grave após ser baleada pelo marido."

o Popular

\begin{tabular}{l|l|l|}
\hline CATEGORIAS & BOLETIM DE OCORRÊNCIA & JORNAL O POPULAR \\
\hline $\begin{array}{l}\text { OQUE É DITO } \\
\text { SOBRE A MULHER }\end{array}$ & $\begin{array}{l}\text { - Em processo de separação por causa } \\
\text { da depressão do ex-marido, voltou a sua } \\
\text { residência para buscar seus pertences e } \\
\text { foi alvejada. }\end{array}$ & $\begin{array}{l}\text { - Senhora de } 59 \text { anos havia saído de } \\
\text { casá alguns dias, mas voltou para } \\
\text { butingida. }\end{array}$ \\
\hline $\begin{array}{l}\text { O QUE É DITO } \\
\text { SOBRE OAGRESSOR }\end{array}$ & $\begin{array}{l}\text { - O agressor estava doente com } \\
\text { depressão e não aceitava o fim do } \\
\text { relacionamento. }\end{array}$ & $\begin{array}{l}\text { - Ele pediu para conversar com a ex- } \\
\text { esposa, efetuou disparos contra ela e } \\
\text { depois se matou. }\end{array}$ \\
\hline
\end{tabular}

Fonte: Pesquisa: A culpabilização das mulheres nas narrativas sobre violência de gênero nos boletins de ocorrência e nos jornais diários de Goiânia (PV0867-2017)

QUADRO 08: "Mãe de gêmeos recebia ameaças pelo Whatsapp."

$$
\text { O Popular }
$$

\begin{tabular}{l|l|l|}
\hline CATEGORIAS & BOLETIM DE OCORRÊNCIA & JORNAL O POPULAR \\
\hline $\begin{array}{l}\text { O QUE É DITO } \\
\text { SOBRE A MULHER }\end{array}$ & $\begin{array}{l}\text { - Teve um relacionamento a moroso com } \\
\text { o autor, após o término, não foi aceito. }\end{array}$ & $\begin{array}{l}\text { - Era ameaçada pelo ex-namorado, e } \\
\text { disse que não acreditava na } \\
\text { gravidade das ameaças. }\end{array}$ \\
\hline $\begin{array}{l}\text { O QUE É DITO } \\
\text { SOBRE OAGRESSOR }\end{array}$ & $\begin{array}{l}\text { - Inconformado com o término, pulou o } \\
\text { muro, arrombou a porta da residência }\end{array}$ & $\begin{array}{l}\text {-Ele disse que ela o estava traindo } \\
\text { arrumando outro homem. }\end{array}$ \\
\hline
\end{tabular}




\section{VOZES $_{\text {\&DÁLORO }}^{\mid}$}

Itajaí, V. 20, n.01, jan-jun 2021

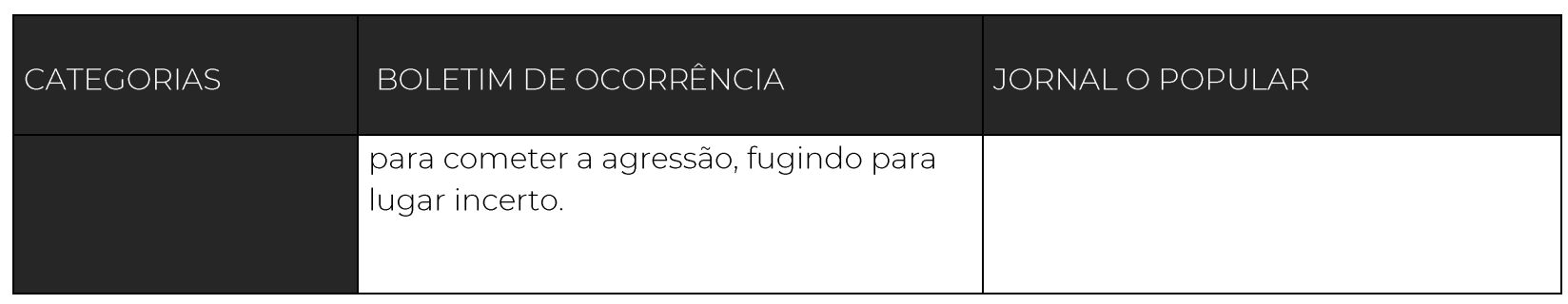

Fonte: Pesquisa: A culpabilização das mulheres nas narrativas sobre violência de gênero nos boletins de ocorrência e nos jornais diários de Goiânia (PV0867-2017)

QUADRO 09: "Bastante ferida, jovem é resgatada após sequestro por ex."

\section{O Popular}

\begin{tabular}{l|l|l|}
\hline CATEGORIAS & BOLETIM DE OCORRÊNCIA & JORNAL O POPULAR \\
\begin{tabular}{l|l} 
O QUE É DITO \\
SOBRE A MULHER
\end{tabular} & $\begin{array}{l}\text { - A vítima foi ameaça pelo ex-namorado, } \\
\text { que chegou com uma tesoura de punho } \\
\text { e a obrigou a subir na moto com ele. }\end{array}$ & $\begin{array}{l}\text { - Marcada pelo medo das constantes } \\
\text { agressões, lara Gabriela Santos } \\
\text { Figueiredo, de 22 anos, resolveu dar } \\
\text { um basta no relacionamento. }\end{array}$ \\
\hline $\begin{array}{l}\text { O QUE É DITO } \\
\text { SOBRE OAGRESSOR }\end{array}$ & $\begin{array}{l}\text { - Bastante violento, os outros parentes } \\
\text { témedo do agressor, que já foi preso } \\
\text { várias vezes por roubo, furto e porte } \\
\text { ilegal de armas. }\end{array}$ & $\begin{array}{l}\text {-A rotina de medo se reforçava ao vê- } \\
\text { lo cometendo crimes com } \\
\text { frequência, apesar de as passagens } \\
\text { pela polícia registrarem apenas a } \\
\text { prática de furto qualificado e porte } \\
\text { ilegal de arma de fogo. }\end{array}$ \\
\hline
\end{tabular}

Fonte: Pesquisa: A culpabilização das mulheres nas narrativas sobre violência de gênero nos boletins de ocorrência e nos jornais diários de Goiânia (PV0867-2017)

QUADRO 10: "Pai teria atirado a sangue-frio na filha."

O Popular

\begin{tabular}{|c|c|c|}
\hline CATEGORIAS & BOLETIM DE OCORRÊNCIA & JORNAL O POPULAR \\
\hline $\begin{array}{l}\text { O QUE É DITO } \\
\text { SOBRE A MULHER }\end{array}$ & $\begin{array}{l}\text { - Ela se mostrava irredutível à ideia de se } \\
\text { reconciliar com o ex-marido, que insistia } \\
\text { sempre. }\end{array}$ & $\begin{array}{l}\text { - Ela vinha sofrendo ameaças do ex- } \\
\text { companheiro. }\end{array}$ \\
\hline $\begin{array}{l}\text { O QUE É DITO } \\
\text { SOBRE O AGRESSOR }\end{array}$ & $\begin{array}{l}\text { - Tratava-se de um crime passional, } \\
\text { tendo o autor atentado contra vida da } \\
\text { ex-mulher. } \\
\text { - Inconformado, ele proferia ameaças } \\
\text { dizendo que, se ela não reatasse o }\end{array}$ & $\begin{array}{l}\text {-Não aceitava do fim do } \\
\text { relacionamento e estava abatido, } \\
\text { pois a ex-companheira estava em } \\
\text { outro relacionamento. }\end{array}$ \\
\hline
\end{tabular}




\section{VOZES $_{\text {\&DÁLORO }}^{\mid}$}

Itajaí, V. 20, n.01, jan-jun 2021

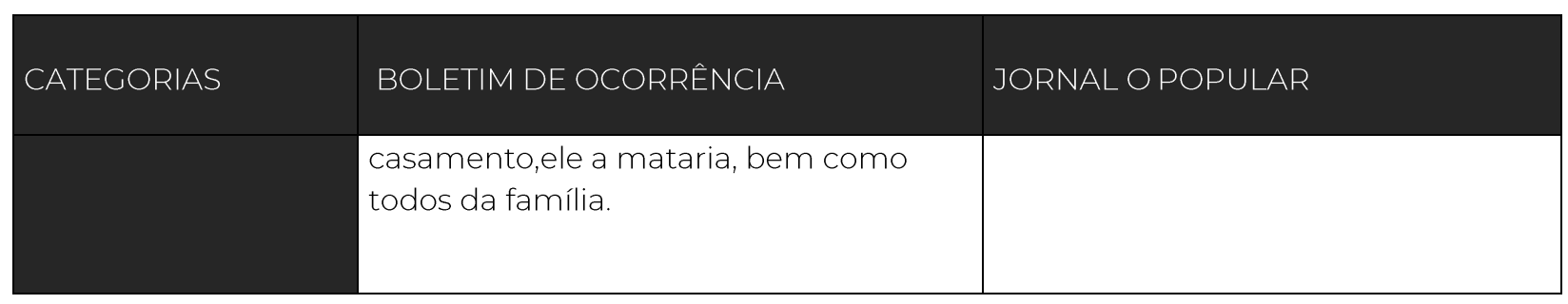

Fonte: Pesquisa: A culpabilização das mulheres nas narrativas sobre violência de gênero nos boletins de ocorrência e nos jornais diários de Goiânia (PV0867-2017)

QUADRO 11: "Homem é preso por agredir e roubar mulher."

O Popular

\begin{tabular}{l|l|l|}
\hline CATEGORIAS & BOLETIM DE OCORRÊNCIA & JORNAL O POPULAR \\
\hline $\begin{array}{l}\text { O QUE É DITO } \\
\text { SOBRE A MULHER }\end{array}$ & $\begin{array}{l}\text { - Ela estava indo para o trabalho quando } \\
\text { foi agredida pelo ex-namorado. }\end{array}$ & $\begin{array}{l}\text { - Ela foi agredida e roubada pelo ex- } \\
\text { namorado. }\end{array}$ \\
\hline $\begin{array}{l}\text { O QUE É DITO } \\
\text { SOBRE O AGRESSOR }\end{array}$ & $\begin{array}{l}\text { - O autor ameaçou a vítima no seu local } \\
\text { de trabalho, vindo a agredi-la, e ainda } \\
\text { roubou sua bicicleta e seu tablet. }\end{array}$ & $\begin{array}{l}\text { - Foi preso em flagrante por agredir e } \\
\text { coubar o tablet e a bicicleta da ex- } \\
\text { compeira. }\end{array}$ \\
& $\begin{array}{l}\text { - O autor tinha várias passagens por } \\
\text { violência doméstica e outros crimes, } \\
\text { além de uma condenação por lesão } \\
\text { corporal. }\end{array}$ \\
\hline
\end{tabular}

Fonte: Pesquisa: A culpabilização das mulheres nas narrativas sobre violência de gênero nos boletins de ocorrência e nos jornais diários de Goiânia (PV0867-2017)

QUADRO 12: "Homem tenta matar atual namorado da ex."

O Popular

\begin{tabular}{l|l|l|}
\hline CATEGORIAS & BOLETIM DE OCORRÊNCIA & JORNAL O POPULAR \\
\hline $\begin{array}{l}\text { OQUE É DITO } \\
\text { SOBRE A MULHER }\end{array}$ & $\begin{array}{l}\text { - Ela estava com o atual namorado em } \\
\text { via pública, quando foi importunada } \\
\text { pelo ex-esposo. }\end{array}$ & $\begin{array}{l}\text { - Ela foi ameaçada e perseguida pelo } \\
\text { ex-companheiro. }\end{array}$ \\
\hline
\end{tabular}




\section{VOZES $_{\text {\&DÁLORO }}^{\mid}$}

Itajaí, V. 20, n.01, jan-jun 2021

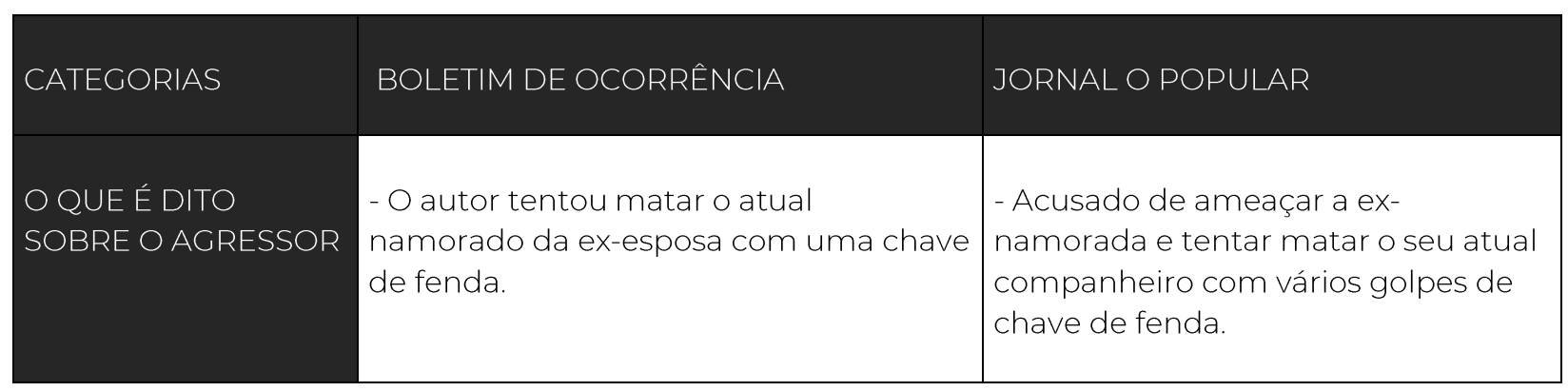

Fonte: Pesquisa: A culpabilização das mulheres nas narrativas sobre violência de gênero nos boletins de ocorrência e nos jornais diários de Goiânia (PV0867-2017)

QUADRO 13: "Mulher foi torturada antes de ter o clitóris mutilado."

O Popular

\begin{tabular}{|c|c|c|}
\hline CATEGORIAS & BOLETIM DE OCORRÊNCIA & JORNAL O POPULAR \\
\hline $\begin{array}{l}\text { O QUE É DITO } \\
\text { SOBRE A MULHER }\end{array}$ & $\begin{array}{l}\text { - Ela estava morando com o autor há } \\
\text { quatro meses e, ao chegar a sua casa, } \\
\text { devido aos ciúmes dele, foi agredida. }\end{array}$ & $\begin{array}{l}\text { - A vítima foi agredida com murros, } \\
\text { chutes, facadas e xingamentos, por } \\
\text { suspeita de traição. }\end{array}$ \\
\hline $\begin{array}{l}\text { O QUE É DITO } \\
\text { SOBRE O AGRESSOR }\end{array}$ & $\begin{array}{l}\text { - Tentou fugir, pegou uma arma branca } \\
\text { e cortou o clitóris dela e a trancou no } \\
\text { quarto, e deixou-a presa por dois dias. }\end{array}$ & $\begin{array}{l}\text { - O ápice da violência aconteceu } \\
\text { quando o suspeito mutilou as partes } \\
\text { íntimas dela. }\end{array}$ \\
\hline
\end{tabular}

Fonte: Pesquisa: A culpabilização das mulheres nas narrativas sobre violência de gênero nos boletins de ocorrência e nos jornais diários de Goiânia (PV0867-2017)

QUADRO 14: "Marido é suspeito de colocar fogo na mulher."

\section{o Popular}

\begin{tabular}{|l|l|l|}
\hline CATEGORIAS & BOLETIM DE OCORRÊNCIA & JORNAL O POPULAR \\
\hline $\begin{array}{l}\text { SOBRE A MULHER } \\
\text { SOE DITO }\end{array}$ & $\begin{array}{l}\text { A vítima foi agredida com fogo no seu } \\
\text { corpo. }\end{array}$ & $\begin{array}{l}\text { - Eliane Souza dos Santos, de } 35 \text { anos, } \\
\text { teve cerca de } 50 \% \text { do corpo } \\
\text { queimado e está internada em } \\
\text { estado grave, porém estável. }\end{array}$ \\
\hline
\end{tabular}




\section{VOZES $_{\text {\&DÁLORO }}^{\mid}$}

Itajaí, V. 20, n.01, jan-jun 2021

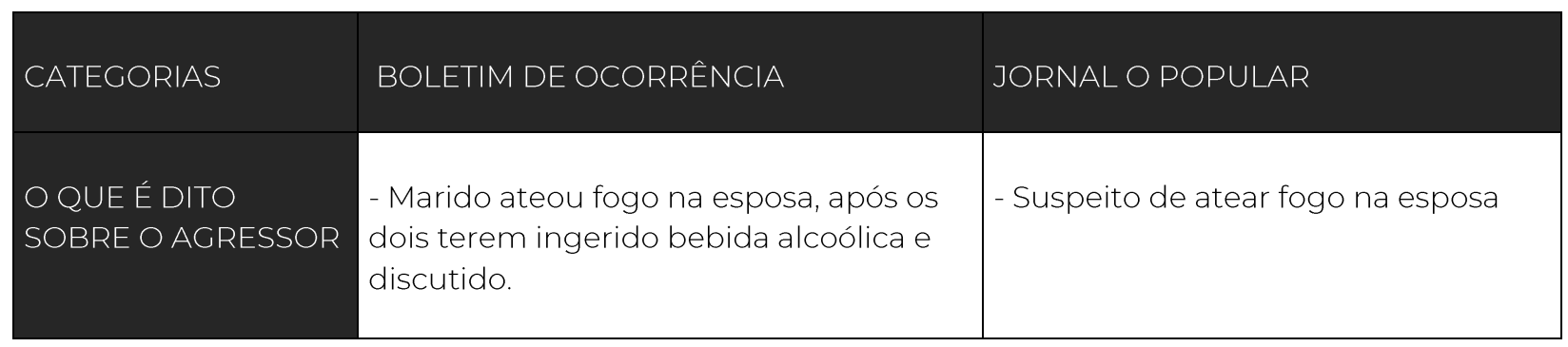

Fonte: Pesquisa: A culpabilização das mulheres nas narrativas sobre violência de gênero nos boletins de ocorrência e nos jornais diários de Goiânia (PV0867-2017)

QUADRO 15: "Homem é preso em Anápolis suspeito de torturar mulher."

O Popular

\begin{tabular}{l|l|l|}
\hline $\begin{array}{l}\text { CATEGORIAS } \\
\text { OOLETIM DE OCORRÊNCIA }\end{array}$ & JORNAL O POPULAR \\
\hline $\begin{array}{l}\text { O QUE É DITO } \\
\text { SOBRE A MULHER }\end{array}$ & $\begin{array}{l}\text { - A vítima estava sendo torturada há } \\
\text { dias, com lesões e hematomas visíveis, } \\
\text { perfuração com faca na coxa esquerda. }\end{array}$ & $\begin{array}{l}\text { - A vítima foi encontrada com } \\
\text { diversos ferimentos pelo corpo, } \\
\text { causados por uma faca, e chegou a } \\
\text { ter as nádegas perfuradas. }\end{array}$ \\
\hline $\begin{array}{l}\text { O QUE É DITO } \\
\text { SOBRE O AGRESSOR }\end{array}$ & $\begin{array}{l}\text { - Verificando uma suposta Maria da } \\
\text { penha, o autor foi preso em flagrante } \\
\text { cárcere privado. }\end{array}$ & $\begin{array}{l}\text { - Unápolis, suspeito de torturar e } \\
\text { manter a companheira de } 39 \text { anos } \\
\text { em cárcere privado. }\end{array}$ \\
\hline
\end{tabular}

Fonte: Pesquisa: A culpabilização das mulheres nas narrativas sobre violência de gênero nos boletins de ocorrência e nos jornais diários de Goiânia (PV0867-2017)

Buscar definir os discursos e suas nuances presentes nos boletins de ocorrência, a fim de identificar as representações sociais de gênero que influenciam as narrativas jornalísticas, é buscar compreender o processo de construção do senso comum por meio da difusão das notícias, que influenciam as ações dos outros na produção e transmissão de formas simbólicas (THOMPSON, 2001). Neste sentido, nas análises de conteúdo realizadas pelas narrativas policiais e jornalísticas, foram utilizados os princípios propostos por Bardin (2016): pertinência, relevância e exclusividade, sendo considerados expressivos dos boletins de ocorrência em cada categoria e, por essa via, reproduzidos pelos jornais.

Na categoria o que é dito sobre a mulher, os dados divulgados pelas narrativas do jornal $O$ Popular retratam a mulher como estando vinculada a muitos casos amorosos, ou casos extraconjugais, revelando que esta mulher não está se comportando como uma mulher virtuosa e disciplinada, ou seja, dentro dos atributos históricos e sociais que foram construídos para o bem da "honra” masculina (BANDEIRA E MAGALHÃES, 2019). Por essa via, existe um liame entre as narrativas analisadas, em que os boletins de ocorrência fornecem os fatos por meio de uma carga sociocultural destacando comportamentos 


\title{
VOZES $_{\text {\&IÁLORO }}^{\mid}$
}

Itajaí, V. 20, n.01, jan-jun 2021

negativos, os quais reafirmam estigmas depreciativos e acabam por entrar no enquadramento midiático pela tragédia da violência, o que compromete - quando não desrespeita - a imagem da mulher (BANDEIRA E MAGALHÃES, 2019).

Ressalta-se ainda que, ao ser comparado com o jornal Diário da Manhã no mesmo lapso temporal, o jornal $O$ Popular possui quase o dobro de publicações sobre casos de violência de gênero com fontes da segurança pública. Desse modo, há uma predominância em $O$ Popular pela pauta dos boletins de ocorrência quando se trata de violência contra mulheres.

\begin{abstract}
As redações e os jornalistas dedicam espaço considerável aos temas relacionados à violência contra as mulheres, uma questão social relevante e de interesse da população. Contudo, há excessiva concentração da cobertura em reportagens, especialmente as de caráter policial, que carecem de contextualização e problematização (SANEMATSU, 2011, p. 67).
\end{abstract}

Apesar de muitos casos noticiados pelo jornal $O$ Popular sobre a violência contra mulheres, pode-se identificar na categoria o que é dito sobre o agressor, no quadro de número 10, um eufemismo utilizado nas narrativas, a saber: Tratava-se de um crime passional, tendo o autor atentado contra vida da ex-mulher; Não aceitava o fím do relacionamento e estava abatido, pois a ex-companheira estava em outro relacionamento; assim há uma naturalização desse tipo de violência, o que contribui para difundir a crença de que não há saídas ou alternativas para a mulher (BANDEIRA E MAGALHÃES, 2019, p. 47).

Por outro lado, se a mulher tenta reagir às condições impostas pelas desigualdades de gênero através de alguns atos de autodefesa, isso pode levar a mais uma forma de revitimização, o que obscurece e nega as relações de poder (GREGORI, 1993), conforme demonstrado no quadro 06: De acordo com a polícia civil, a motivação do crime teria sido porque a vítima teria ameaçado a mulher do homem de morte; $O$ agressor havia colado os olhos, genitália e ânus da vítima com Super Bonder. A perspectiva que obscurece as relações de poder predominantes entre os gêneros nestas formas de violência não leva em conta as condições e as situações do medo, do terror sobre a vítima, e as consequências do medo no relacionamento (BANDEIRA E MAGALHÃES, 2019, p. 47).

Ainda, ao observar as categorias de análise, verifica-se que as narrativas policiais, em termos gerais, apresentam elementos como motivação do crime em expressões como: crime passional, ciúmes, autor fora de si ou descontrolado (PRADO E SANEMATSU, 2017, p. 148), e alguns casos agravados pelo uso de bebida.

Verifica-se que os discursos das narrativas policiais são construídos por meio de uma carga sócio-histórica que retrata a mulher em uma condição de pertencimento ao homem, que tinha extremo controle sobre o seu corpo e a sua sexualidade, sendo ela mantida em permanente ameaça pela masculinidade (BANDEIRA E MAGALHÃES, 


\section{VOZES $_{\text {\&IÁLORO }}^{\mid}$}

Itajaí, V. 20, n.01, jan-jun 2021

2019). As matérias jornalísticas não ajudam a desenvolver uma narrativa que colabore para uma reflexão das desigualdades de gênero, construídas socialmente e historicamente na sociedade.

A partir da análise dos elementos da construção social das notícias veiculadas pelo jornal $O$ Popular, foi verificado também que essas são capazes de não apenas publicizar casos de violência contra mulheres no estado de Goiás, como também reproduzir e legitimar por meio dos discursos e vias simbólicas a dominação masculina, que está alicerçada na estrutura cultural da diferença sexual, sendo determinante para direcionar os papéis destinados aos homens e as mulheres (BOURDIEU, 2015).

Bandeira e Magalhães (2019), ao mencionar Savietto (2015), ressaltam que os significados pelas representações negativas sobre o feminino acabam por moldar e definir os padrões de comportamentos deturpados sobre as mulheres. Assim, a construção social das mulheres é produzida pelas práticas e representações simbólicas dentro de formações sociais dadas, ou seja, nos casos analisados, os boletins de ocorrência produzem os papéis e as prescrições sociais dadas às mulheres, e os jornais apenas reproduzem essas práticas (LAMAS, 2000). Fatos como a desqualificação ou culpabilização da mulher, ou mesmo a justificativa do agressor, implicam a transmissão de uma mensagem de menor importância do ato criminoso (BANDEIRA E MAGALHÃES, 2019).

No que diz respeito ao quadro de número 10, no qual se lê a seguinte manchete "Pai teria atirado a sangue-frio na filha", a partir da leitura da matéria, depreende-se que o ex-marido não aceitava o fim do relacionamento, estava deprimido, pois a ex-esposa estava se relacionamento com outro homem, e assim ele atirou em todos da família e veio a se suicidar. A este respeito, a notícia foi explorada de maneira atroz pelo jornal O Popular ao destacar o sofrimento do agressor pelo fato de a ex-mulher não querer reatar o relacionamento, e ainda pode-se ler um discurso subliminar de que a mulher era responsável pela destruição de uma família - culpabilização e desqualificação da mulher.

Bandeira e Magalhães (2019), ao analisar os crimes cometidos contra mulheres no Brasil e Portugal que resultam no suicídio ${ }^{3}$ do agressor, ressaltam que há fatos recorrentes em que o agressor, depois de cometer o crime, acaba se suicidando, o que pode detonar uma condição de arrependimento ou um ato de covardia para o não enfrentamento das consequências, ou ainda, a não superação do sofrimento. Neste contexto, a construção da narrativa do jornal $O$ Popular seguiu a trajetória de toda narrativa policial, em que a atitude do agressor é justificada pelo sofrimento extremo com o argumento de que ele queria apenas restaurar sua família, e pela culpabilização e desqualificação da mulher, pois, segundo a narrativa policial: Ela se mostrava irredutível à ideia de se reconciliar com o ex-

\footnotetext{
${ }^{3}$ Há pesquisadoras/es, no campo da psicologia clínica, que afirmam, sobre o ato de suicidar-se, que o crime cometido pode gerar uma situação potencial de estresse no homem ao tomar "consciência" do ocorrido, levando-o a acabar com a própria vida (BANDEIRA; MAGALHÃES, 2019, p. 46).
} 


\title{
VOZES $_{\text {\&IÁLORO }}^{\mid}$
}

Itajaí, V. 20, n.01, jan-jun 2021

marido, que insistia sempre. $\mathrm{E}$ ainda, de acordo com a narrativa policial, trata-se de um crime passional: Tratava-se de um crime passional, tendo o autor atentado contra a vida da ex-mulher. Inconformado, ele proferia ameaças dizendo que, se ela não reatasse o casamento, ele a mataria, bem como todos da família (Quadro 10).

Todavia, segundo o entendimento de Bandeira e Magalhães (2019), fundamentado no entendimento de Campos (2018), a categoria de crime passional é nominação de senso comum e continua associada a um estado de "transtorno" do masculino:

\begin{abstract}
Não existe "crime passional" na legislação penal brasileira. O que existe é uma previsão de diminuição de pena, chamada de circunstância atenuante, art. 65, c, do Código Penal, que diz o seguinte: art. 65: "São circunstâncias que sempre atenuam a pena: c) cometido o crime... sob a influência de violenta emoção provocada por ato injusto da vítima. Essa atenuante era utilizada para justificar os "crimes passionais", ou seja, "crimes de paixão", isto é, aqueles cometidos sob suposta "violenta emoção", após injusta provocação da vítima. Essa "injusta provocação" era entendida como "adultério" etc. Então, o crime passional é uma invenção fundamentada nessa atenuante. $\mathrm{E}$ mais, os ditos "crimes passionais”, na verdade, são homicídios qualificados, porque são sempre planejados. O homem compra a arma, espera a vítima, atrai a vítima para o lugar, e acaba por cometer o crime. $\mathrm{O}$ componente de vingança também está presente (BANDEIRA E MAGALHÃES 2019, p. 42 apud CAMPOS 2018).
\end{abstract}

Desse modo, o enredo do quadro 32 é noticiado com os mesmos contornos dados pelo boletim de ocorrência, ou seja, a morte da filha remete à culpa da mulher pelo fracasso social e insucesso da família, o suicídio do agressor reporta à culpa da mulher pelo fracasso na relação conjugal, já que o ex-companheiro insistiu em reatar o casamento, mas ela não quis por ter atitudes inadequadas para uma mulher, como um possível caso extraconjugal, o que teria motivado os ciúmes do marido.

Segundo Prado e Sanematsu (2017), há uma falta de abordagem crítica e a ausência de um debate aprofundado na mídia sobre crimes contra mulheres, assim a imprensa não cumpre o papel de cobrar soluções que evitem novas ocorrências desses crimes. Para os autores, a imprensa pode fazer diferença ao dar visibilidade às diferentes dimensões desses crimes, quando se evidencia o menosprezo ou discriminação à condição de mulher. Ainda, para Pasinato (2011), é fundamental que a mídia trabalhe com respeito à memória das vítimas. Deve-se preservar a privacidade, ter respeito pela intimidade, não explorar fatos da vida íntima, principalmente da vida sexual, do comportamento sexual dessa vítima. Segundo a autora, vender o caso não contribui em nada para que se tenha uma resposta judicial à altura do crime.

Posto isso, quando a notícia traz todos esses elementos, consolida o processo de revitimização como reflexo da violência simbólica ao enfatizar que o agressor só agiu por forte emoção (crime passional), e a mulher poderia ter evitado a morte de sua filha e o 


\section{VOZES

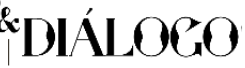

Itajaí, V. 20, n.01, jan-jun 2021

suicídio do agressor, se tivesse tomado uma atitude diferente (reatado o casamento), tornando-a, assim, responsável pela violência que atingiu todo seu contexto familiar.

Desse modo, as "relações de poder que atuam ainda a partir da crença na inferioridade ou subordinação da mulher, desconsiderando e desvalorizando suas experiências histórico-culturais, seus valores e interesses singulares em detrimento àqueles masculinos" (BANDEIRA E MAGALHÃES, 2019, p.48 apud BANDEIRA E ALMEIDA, 2016). Assim, a construção social e práticas em torno das diferenças entre os sexos (LAMAS, 2000) ganha contornos visíveis pelas análises das narrativas, em que determinados enredos, em detrimento de outros, são capazes de endossar ou silenciar os sujeitos pelas diferenças sexuais.

Pode-se inferir pelas análises realizadas que tanto nas narrativas dos boletins de ocorrência quanto nas narrativas dos jornais Diário da Manhã e O Popular há uma inversão da culpa e desqualificação por meio da responsabilização dessas mulheres pela violência sofrida, o que se torna um obstáculo para a devida punição do agressor, como também para garantir que essas mulheres recebam uma proteção adequada para romper com o ciclo da violência a que são submetidas. Ainda, as narrativas remetem um juízo de valor associadas aos contextos "generalizados para além do ódio e desprezo, mas também de desqualificação, hostilidade e discriminações sobre as mulheres” (BANDEIRA E MAGALHÃES, 2019, p.47).

\section{Considerações finais}

Neste artigo, procurou-se estudar a violência simbólica de mulheres em situação de violência como um reflexo da revitimização por meio das narrativas dos boletins de ocorrência que foram reproduzidos por meio das narrativas do jornalismo impresso goiano.

Foram analisadas 15 narrativas policiais e jornalísticas de dois veículos de maior circulação do estado - O Popular e O Diário da Manhã no lapso temporal 2016 a 2017. O objetivo foi o de compreender como a revitimização (compreendida como o processo em que as mulheres permanecem no ciclo de violência - produzida, também, pelas narrativas dos boletins de ocorrência) é mobilizada nas narrativas jornalísticas analisadas de maneira a legitimar a violência simbólica contra essas mulheres.

A partir das análises das narrativas policiais e jornalísticas, ficou demonstrado que o boletim de ocorrência como fonte das notícias interfere na representação social sobre os papéis de gênero e comportamentos socialmente esperados por mulheres em situação de violência, e que as vítimas acabam sendo responsabilizadas pela violência que sofrem quando elas não se enquadram nesses estereótipos (PRADO E SANEMATSU, 2017). Cabe frisar, que há semelhança entre as narrativas policiais e jornalísticas, segundo Bandeira e Magalhães (2019, p. 49), se orientam na centralidade do crime e nos 


\section{VOZES $_{\text {\&IÁLORO }}^{\mid}$}

Itajaí, V. 20, n.01, jan-jun 2021

"personagens centrais - no ato homem-agressor, referido ao 'culto viril', desconsiderando, muitas vezes, sua trajetória, assim como as relações de poder que lhe são investidas.”

Concluiu-se que as matérias jornalísticas apresentam conteúdos e narrativas estruturadas a partir de regimes simbólicos correntes em outros campos da vida social, agindo de forma a naturalizar relações violentas e desiguais. Neste processo, as dinâmicas jornalísticas e policiais também assumem o papel de agentes de violência, numa dimensão simbólica - naturalizando as desigualdades de gênero.

\section{REFERÊNCIAS}

BAIRROS, L. A participação das mulheres negras nos espaços de poder. Brasília: Secretaria Especial de Políticas para Mulheres. 2000. Disponível: https://www.gov.br/mdh/pt-br/centrais-de-conteudo/igualdade-racial/a-participacaodas-mulheres-negras-nos-espacos-de-poder/view. Acesso 11 de março de 2020.

BANDEIRA, L. et al. Preconceito e discriminação como expressões de violência. Rev. Estud. Fem., vol. 10, n. 1, Florianópolis, jan. 2002. Disponível em: http://www.scielo.br/scielo.php?script=sci_arttext\&pid=S0104-026X2002000100007. Acesso em: 21 nov. 2019.

BANDEIRA, L.M. Violência de gênero: a construção de um campo teórico e de investigação. Sociedade e Estado, Brasília, v. 29, n. 2, p. 449-469, mai./ago. 2014.

BANDEIRA, L.M. Violência feminicida: reflexão emergente sobre a morte violenta de mulheres. Brasília, 2016.

BANDEIRA, L.M. Violência, gênero e poder: múltiplas faces. Mulheres e violências: interseccionalidades. Brasília, DF: Technopolitik, 2017.

BANDEIRA, L. M.; MARTIN S, A.P. M. A violência contra as mulheres: crimes de feminicídio e seu enquadramento midiático. In: BELISÁRIO, K.M. (Coord. e Org.). Gênero em pauta. Desconstruindo violências, construindo novos caminhos. São Paulo: Appris, 2019.

BANDEIRA, L.M.; MAGALHÃES, M. J. A transversalidade dos crimes de feminicídio/femicídio no Brasil e em Portugal. Revista da Defensoria Pública do Distrito Federal, Brasília, v. 1, n. 1, 2019, p. 29/56.

BARDIN, L. Análise de conteúdo.70. ed. Lisboa, Portugal: LDA, 2016. 


\section{VOZES $_{\text {\&IÁLORO }}^{\mid}$}

Itajaí, V. 20, n.01, jan-jun 2027

BOURDIEU, P. A dominação masculina: a condição feminina e a violência simbólica. 1. ed. Rio de Janeiro: Bestbolso, 2015.

CARNEIRO, S. Mulheres em movimento. Estudos Avançados, v. 17, n. 49, p. 117 137, 2003.

CHAUÍ, M. Uma ideologia perversa. Explicações para a violência impedem que a violência real se torne compreensível. Folha de S. Paulo, São Paulo, 14 mar. 1999, Caderno Mais! p. 5-3

CUNHA, R.S.; PINTO, R.B. Violência Doméstica: Lei Maria da Penha (Lei 11.340/2006), comentada artigo por artigo. 2. ed. São Paulo: Revista Dos Tribunais, 2008.

DIAS, M.B. A Lei Maria da Penha na Justiça: a efetividade da Lei 11.340/2006 de combate à violência doméstica e familiar contra a mulher. 4. ed. São Paulo, SP: Revista dos Tribunais, 2018.

GOMES, L. S.; MIRANDA, C. M. A mulher, o coturno e mídia: experiências de um comando militar feminino. In: PÔRTO JR., G. et al. Comunicação e sociedade: discussões sobre práticas e impactos da comunicação e do cotidiano. Porto Alegre, RS: Editora Fi, 2017.

GREGORI, M.F. Cenas e queixas um estudo sobre mulheres, relações violentas e a prática feminista. São Paulo: Paz e Terra, 1993.

GUIMARÃES, I. P. A imagem da violência urbana no documentário cinematográfico brasileiro na contemporaneidade. Tese (Doutorado em Comunicação) Faculdade de Comunicação, PUCRS. Porto Alegre, 2010.

HEISE, L. PITANGUY, J. GERMAIN, A. Violência Contra la Mujer: La Carga oculta sobre la Salud. Banco Mundial, 1998, Washington D.C.

INSTITUTO PATRÍCIA GALVÃO. Diretrizes Nacionais do Feminicídio: uma análise de sua implementação no estado de São Paulo - SP, 24/10/2017. Publicado em 17/10/2017. Disponível em: http://www.agenciapatriciagalvao.org.br/ dossies/feminicidio/diretrizes-nacionais/. Acesso em: 04 jul. 2020. 


\section{VOZES $_{\text {\&IÁLORO }}^{\mid}$}

Itajaí, V. 20, n.01, jan-jun 2027

JORNALISTA EXTERNO. Estatuto da Mulher Casada comemora 45 anos nesse

mês. Tribuna, 23 ago. 2007, às 18h32. Disponível em: https://www.tribunapr.com.br/noticias/mundo/estatuto-da-mulher-casada-comemora-45anos-nesse-mes/. Acesso em: 02 dez. 2019.

LAMAS, M. Diferencias de sexo, género y diferencia sexual. Nueva Época, v. 7, n. 8, 2000/2001. Disponível em: https://www.redalyc.org/pdf/351/35101807.pdf. Acesso em: 05 jan. 2020.

LAVORENTI, W. Violência e discriminação contra a mulher: tratados internacionais de proteção e o direito penal brasileiro. Campinas, SP: Millennium, 2009.

LIMA, A. P. de. A notícia de violência contra a mulher e a violência da notícia. UFG: 2001, dissertação de mestrado.

LOURO, G. L. Gênero, sexualidade e educação: uma perspectiva pósestruturalista.Petrópolis, RJ: Vozes, 1997.

LOURO, G. L.;NECKEL, J. F.;GOELLNER, V. S. Corpo, Gênero e Sexualidade: um debate contemporâneo na educação. Petrópolis, RJ: Vozes, 2018.

LOURO, G. L. Pedagogias da Sexualidade. In: (Org.). O corpo educado: pedagogias da sexualidade. Tradução dos artigos: Tomaz Tadeu da Silva. 2. ed. Belo Horizonte: Autêntica, 2001. p. 07-34

PASINATO, W. "Femicídios e as mortes de mulheres no Brasil”. Cadernos Pagu, no 37, 2011, p. 219-246. Disponível em http://www.scielo.br/pdf/cpa/n37/a08n37.pdf. Acesso em: 17 out. 2019.

Oito anos de Lei Maria da Penha. Entre avanços, obstáculos e desafios. Estudos Feministas, Florianópolis, v.23, n.2, p. 533-545, 2015.

. W. Dez anos de Lei Maria da Penha. O que queremos comemorar? SUR, v. 13 , n. 24 , p. 155-163, 2016.

PEREIRA, E. M. Psicologia social dos estereótipos. São Paulo: EPU, 2002. 


\section{VOZES $_{\text {\&DÁLORO }}^{\mid}$}

Itajaí, V. 20, n.01, jan-jun 2027

PESQUISA, A culpabilização das mulheres nas narrativas sobre violência de gênero nos boletins de ocorrência e nos jornais diários de Goiânia. Faculdade de informação e comunicação. (PV0867-2017). 2017/2021.

PRADO, D.; SANEMATSU, M. (Org.). Feminicídio: invisibilidade mata. São Paulo: Editora Fundação Rosa Luxemburgo, Instituto Patrícia Galvão, 2017. Disponível em: https://agenciapatriciagalvao.org.br/wpcontent/uploads/2017/03/LivroFeminicidio_InvisibilidadeMata.pdf. Acesso em: 07 jun. 2020.

ROSSI, G. A culpabilização da vítima no crime de estupro: os estereótipos de gênero e o mito da imparcialidade jurídica. Florianópolis: Empório do direito, 2016.

SAFFIOTTI, H.I.B. Gênero, Patriarcado, Violência. São Paulo: Fundação Perseu Abramo, 2004.

SANEMATSU, M. Imprensa e agenda de direitos das mulheres: uma análise das tendências da cobertura jornalística. Coordenação VeetVivarta. Brasília, DF: ANDI, Instituto Patrícia Galvão, 2011.

SEGATO, R. L. "Femigenocidio y feminicidio: una propuesta de tipificación". In: Labrys Estudos Feministas, Brasília, Montreal, Paris, n. 24, jul.-dez. 2013. Edição digital. Disponível em: Disponível em: https://www.labrys.net.br/labrys24/feminicide/rita.htm . Acesso em 11/04/2020.

SEVERI, F. C. Lei Maria da Penha e o projeto jurídico feminista brasileiro. Editora Lumen Juris, Rio de Janeiro, 2018.

THOMPSON, J. A mídia e a modernidade: uma teoria social da mídia/ John B. Thompson; tradução Wagner de Oliveira Brandão; revisão da tradução Leonardo Avritzer. 12ª Ed- Petrópolis, RJ: Vozes, 2001. 